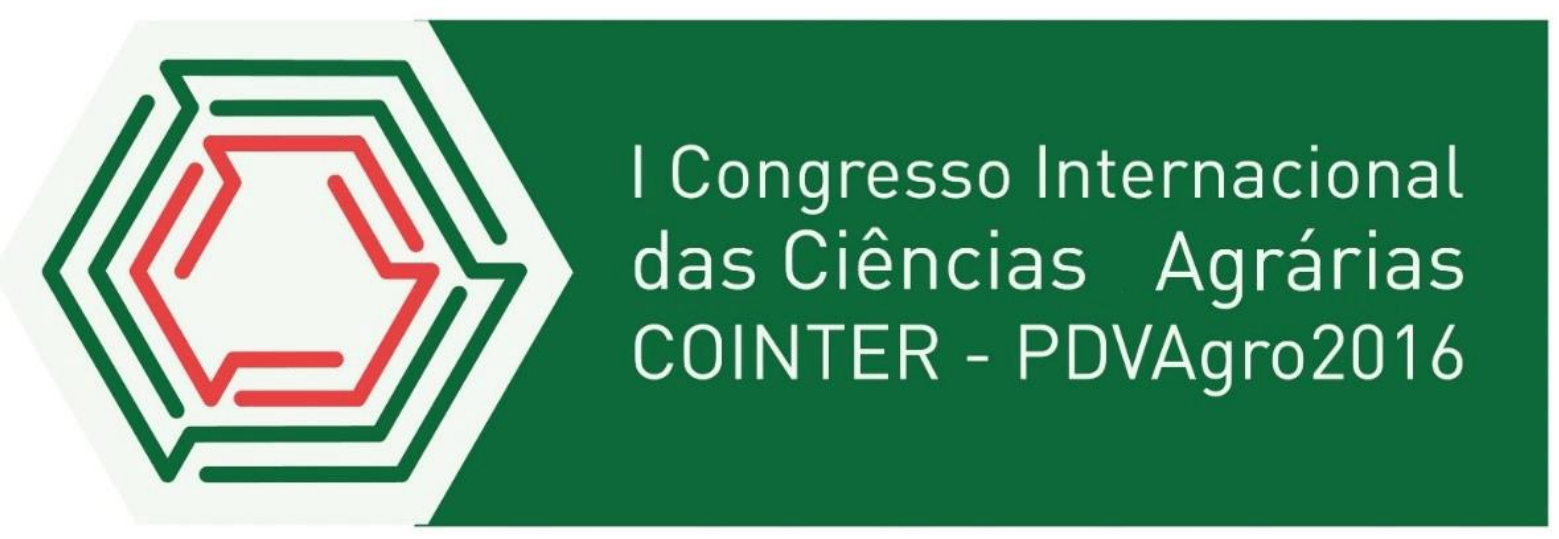

\title{
BIOMETRIA DE PLANTAS E ÍNDICE DE VELOCIDADE DE GERMINAÇÃO EM SEMENTES DE PIMENTÃO ORGÂNICO
}

\author{
Apresentação: Comunicação Oral \\ SÉFORA CORDEIRO SUASSUNA ${ }^{1}$; JEFESSON TORQUATO LEITE \\ GONÇALVES $^{1}$ IURIAN ACIOLI DE OLIVEIRA ${ }^{1}$; WELLINGTON ANDRADE DA \\ CUNHA $^{1}$; RAIMUNDO ANDRADE ${ }^{2}$
}

Resumo: O pimentão, Capsicum annuum L. pertence à família botânica Solanaceae. É uma hortaliça que apresenta grande importância socioeconômica no Brasil, é muito comercializada como fruto verde, vermelho, amarelo, laranja, creme e roxo. O uso de adubos orgânicos de origem animal pode se tornar uma prática útil para os pequenos e médios produtores de pimentão orgânico, dessa forma contribui para melhorar a fertilidade e a conservação do solo tendo assim maior aproveitamento dos recursos que existem na propriedade e de custos baixo para os horticultores de base familiar. O objetivo deste trabalho foi avaliar o crescimento do pimentão e índice de velocidade de emergência sob diferentes doses de biofertilizante e tipos de substratos no crescimento de mudas de pimentão orgânico no município de Catolé do Rocha/PB. O experimento foi conduzido em casa de vegetação da Universidade Estadual da Paraíba, Campus IV, Catolé do Rocha/PB. Utilizou-se o delineamento inteiramente casualizado (DIC), com quatro repetições, totalizando 16 tratamentos e 64 parcelas experimentais. O manejo da irrigação foi manual, utilizando-se um regador para a realização das regas, obedecendo dois turnos de rega, manhã e tarde. A cultivar de pimentão utilizada foi a All Big. A avaliação de crescimento e índice de velocidade de emergência foi realizada mensurando-se: diâmetro caulinas (DC) em mudas de pimentão e o índice de velocidade de emergência em sementes de pimentão orgânico. o índice de velocidade de germinação (IVG), avaliado com a contagem feita diariamente das plântulas que germinaram, até quando os cotilédones não estavam mais em contato com o substrato. Para o parâmetro diâmetro caulinar das plantas o melhor tratamento foi $15 \mathrm{ml} /$ planta vez de biofertilizante. Para o parâmetro índice de velocidade de germinação o melhor tratamento foi o tipo de substrato $\left(\mathrm{S}_{4}\right) 75 \%$ de húmus e $25 \%$ de solo.

Palavras chave: crescimento, biofertilizante, substratos. 


\section{Introdução}

O pimentão, Capsicum annuum L. pertence à família botânica Solanaceae. É uma hortaliça que apresenta grande importância socioeconômica no Brasil, é muito comercializada como fruto verde, vermelho, amarelo, laranja, creme e roxo. Além disso, a cloração influencia no sabor e aroma do fruto (FRIZZONE; GONÇALVES; REZENDE, 2001).

O substrato para plantas pode ser definido como o meio em que as raízes das plantas conseguem se desenvolver fora do solo in situ (KÄMPF, 2000), sendo sua principal função a de promover suporte às plantas nele cultivadas (Kämpf, 2000), além de poder regular a disponibilidade de nutrientes (KÄMPF, 2000) e de água (FONTENO, 1996).

Além disso, o substrato tem o objetivo de proporcionar condições viáveis à germinação e desenvolvimento inicial da muda; é importante para que as raízes das plantas se desenvolvam bem, devendo apresentar baixa densidade, boa capacidade de absorção e retenção de água, boa aeração e drenagem para evitar o acúmulo de umidade, além de estar isento de pragas, doenças e substâncias tóxicas (KÄMPF, 2000; WENDLING; GATTO, 2002).

Uma das principais etapas do sistema produtivo do pimentão é a produção de mudas de qualidade, pois delas depende o desempenho final das plantas no campo de produção (ANDRIOLO, 2000).

O biofertilizante é um insumo orgânico de baixo custo, resultante da fermentação anaeróbica de uma mistura de partes iguais de esterco fresco de bovino e água em biodiestor durante um período de 30 dias (SANTOS e AKIBA, 1996).

A utilização de estercos e outros compostos orgânicos apresenta-se como alternativa promissora capaz de reduzir as quantidades de fertilizantes químicos a serem aplicados (ALMEIDA et al., 1982; SILVA JÚNIOR, 1986; MUNIS et al.,1992).

A partir dessa premissa, objetivou-se analisar o efeito de diferentes dosagens de biofertilizante comum e composição de substratos orgânicos sob formas de adubação em sistemas agroecológicos no cultivo de pimentão em ambiente protegido.

\section{Fundamentação Teórica}

O pimentão (Capsicum annuum L.) é uma solanácea perene, cultivada como cultura anual. Os maiores produtores mundiais são México, Estados Unidos, Itália, Japão, Índia e Brasil (SILVA et al., 1999)

O pimentão apresenta melhor desenvolvimento e produção quando cultivado em ambientes com temperaturas variando entre $20^{\circ} \mathrm{C}$ e $30^{\circ} \mathrm{C}$. Temperaturas inferiores a $15^{\circ} \mathrm{C}$ são limitantes nas fases de germinação, emergência e crescimento das mudas e, acima de $35^{\circ} \mathrm{C}$ 
ocorre queda de flores das plantas (Pereira, 1990). Diferenças entre as temperatura diurna e noturna de até $6^{\circ} \mathrm{C}$ favorecem o bom desenvolvimento da cultura e, embora ocorra floração em qualquer comprimento do dia, a planta apresenta precocidade produtiva quando cultivada em períodos de dias curtos. A umidade relativa do ar ideal para produção de pimentão fica entre $50 \%$ e $80 \%$. Acima do limite superior o ambiente pode favorecer o desenvolvimento de doenças e, abaixo, as plantas transpiram acima do normal (FILGUEIRA, 2003).

A irrigação é imprescindível à produção em ambiente protegido, principalmente para a cultura do pimentão que é altamente exigente em água, sendo necessário suprimento regular durante todo o seu ciclo (Cantuário, 2012). Para melhor desenvolvimento da planta, a umidade do solo deve ser mantida próximo a $80 \%$ da umidade na capacidade de campo, durante o período de frutificação e colheita. Entretanto, tanto à falta de água no solo como seu excesso pode reduzir a produtividade da cultura (SOUZA et al., 2011).

\section{Metodologia}

A pesquisa foi desenvolvida no setor de viveiricultura, na Escola Agrotécnica do Cajueiro, pertencente a Universidade Estadual da Paraíba, distando $02 \mathrm{~km}$ da sede do município de Catolé do Rocha/PB, cujo as coordenadas geográficas são $\left(6^{0} 20^{\prime} 38^{\prime \prime}\right.$ de latitude sul; $37^{0} 44^{\prime} 48^{\prime \prime}$ ' a oeste do meridiano de Greenwich com uma altitude de $275 \mathrm{~m}$ acima do nível do mar.

O delineamento experimental utilizado foi o inteiramente casualizado (DIC), com quatro repetições e 64 plantas experimentais, em arranjo fatorial de $4 \times 4$ totalizando 16 tratamentos. Os tratamentos foram referentes a quatro doses de biofertilizante via solo $\left[\left(\mathrm{D}_{1}=\right.\right.$ $0,0 \quad(\mathrm{~mL} / \mathrm{planta} / \mathrm{vez}) ; \quad \mathrm{D}_{2}=5,0 \quad(\mathrm{~mL} /$ planta/vez $) ; \quad \mathrm{D}_{3}=10,0 \quad(\mathrm{~mL} /$ planta/vez$) ; \quad \mathrm{D}_{4}=15,0$ $(\mathrm{mL} /$ planta/vez $))]$, e quatro substratos $\left(\mathrm{S}_{1}=100 \%\right.$ de solo; $\mathrm{S}_{2}=50 \%$ de solo $+50 \%$ de húmus; $\mathrm{S}_{3}=75 \%$ de solo $+25 \%$ de húmus e $\mathrm{S}_{4}=75 \%$ de húmus $+25 \%$ de solo) no crescimento de plantas de pimentão orgânico.

\section{Resultados e Discussão}

A evolução do diâmetro do caule de plantas de pimentão orgânico, em relação às dosagens de biofertilizante comum, teve um comportamento linear positivo (Figura 01). Observa-se que o diâmetro do caule da planta foi aumentando de forma significativa com o incremento das doses de biofertilizante, tendo havido acréscimo de $0,0788 \mathrm{~mm}$ por aumento unitário das doses de biofertilizante em plantas de pimentão, atingindo, no nível máximo $\left(\mathrm{D}_{4}=\right.$ $15 \mathrm{~mL} /$ planta/vez), à média de $0,22 \mathrm{~m}$. Possivelmente, esse aumente ocorreu devido à 
possibilidade de uma maior solubilização de nutrientes pelo efeito da quelatação imediata do complexo de moléculas orgânicas e mobilização de nutrientes para os sistemas das plantas Dosani et al. (1999), propiciando melhoria crescente das condições físicas, químicas e biológicas do solo, ao longo do tempo (SANTOS, 1992; MIELNICZUK, 1999; DAMATTO JÚNIOR et al; 2009). Conforme (Figura 02), não houve efeito significativo, apresentou similaridade no comportamento dos tratamentos em função da aplicação de diferentes substratos na cultura do pimentão orgânico.

Figura 01. Aplicação de dosagens de biofertilizante no diâmetro caulinar de plantas de pimentão orgânico.

Figura 02. Aplicação de substratos no diâmetro caulinar de plantas de pimentão orgânico.
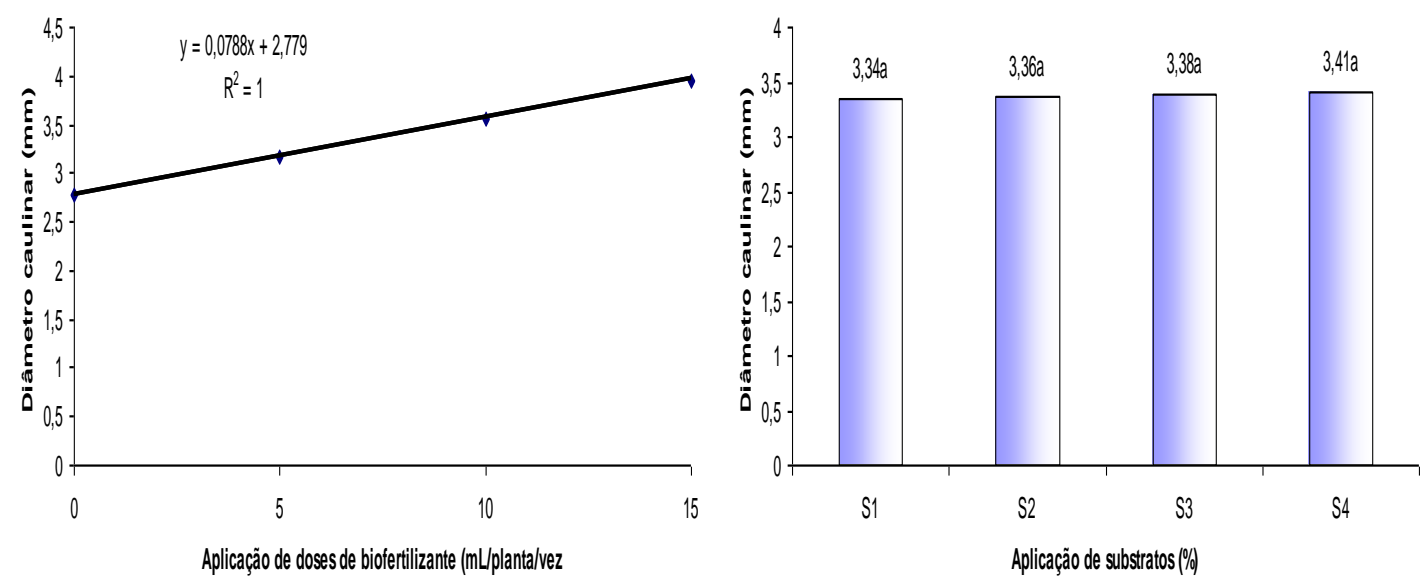

A evolução do índice de velocidade de germinação de sementes de pimentão, teve um comportamento linear crescente (Figura 03). Observa-se que o IVG aumentou de forma significativa com o incremento das doses de biofertilizante, tendo havido acréscimo de 0,0066 $\%$ por aumento unitário das doses de biofertilizante em tratamentos de sementes de pimentão, atingindo, no nível máximo $\left(\mathrm{D}_{4}=15 \mathrm{~mL} / \mathrm{planta} / \mathrm{vez}\right.$, à média de $0,22 \%$. Conforme (Figura 04), houve efeito significativo, onde apresentou destaque para o tratamento $\left(S_{4}\right) 75 \%$ de húmus $+25 \%$ de solo em comparação a aplicação de diferentes substratos na cultura do pimentão orgânico.

Figura 03. Aplicação de dosagens de biofertilizante no IVG em sementes de pimentão orgânico.
Figura 04. Aplicação de substratos no IVG em sementes de pimentão orgânico. 

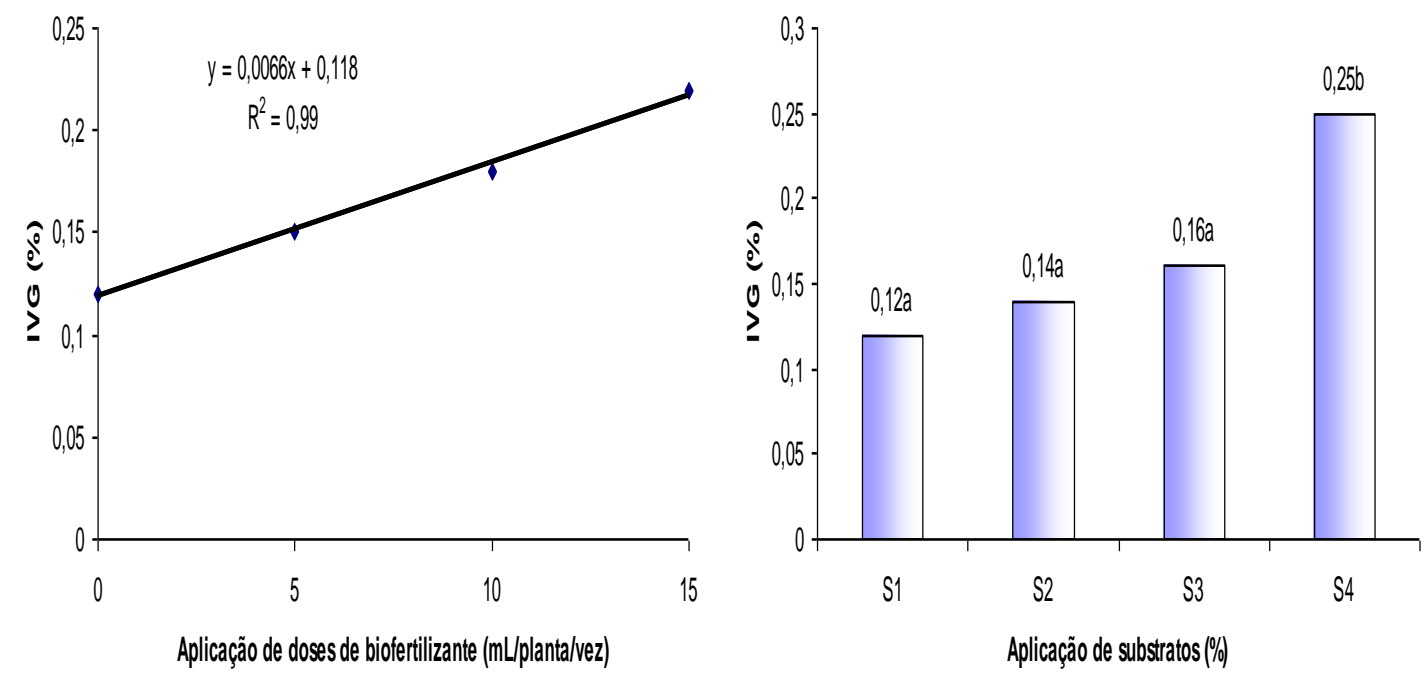

\section{Conclusões}

A dose $15 \mathrm{~mL} /$ planta/vez de biofertilizante comum obteve o valor médio de 3,96 mm no diâmetro caulinar de mudas de pimentnão e valor médio de 0,22 \% no índice de velocidade de germinação;

Os substratos apresentaram similaridade nos diferentes tratamentos, não apresentando efeito significativo em função do diâmetro caulinar de plantas de pimentão orgânico.

O substrato apresentou destaque para o tratamento $\mathrm{S}_{4}(75 \%$ de húmus $+25 \%$ de solo), apresentando efeito significativo em função do IVG.

\section{Referências}

ALMEIDA, D.L.; MAZUR, N.P.; PEREIRA, N.C. Efeitos de composto de resíduos urbanos em cultura do pimentão no município de Teresópolis-RJ. In: CONGRESSO BRASILEIRO DE OLERICULTURA, 22, Vitória. Resumos. Vitória: SOB/SEAG-ES, 1982 p. 322.

ANDRIOLO, J.L. Fisiologia da produção de hortaliças em ambiente protegido. Horticultura Brasileira, Brasília, v.18, supl, p.26-32, 2000.

CANTUÁRIO, F. S. Produção de pimentão submetido a estresse hídrico esilicato de potássio em cultivo protegido. 2012. 93 f. Dissertação (Mestrado em Agronomia) Universidade Federal de Uberlândia, Uberlândia, 2012.

DAMATTO, JÚNIOR, E. R.; NOMURA, E. S.; SAES, L. A. Experiências com o uso de adubação orgânica na cultura da banana. In: GODOY, L. J. G.; GOMES, J. M. Tópicos sobre nutrição e adubação da banana. Botucatu/SP: FEPAF/UNESP, 2009. 143p.

DOSANI, A. A. K.; TALASSHILKAR, S. C.; MEHTA, V. B. Efect of organic mamure applied in combination with fertilizers on the yield, quality and nutrient of groundnut. $\mathbf{J}$. Indian Soc. Soil Sci., v. 47, p. 166-169, 1999. 
FONTENO, W. C. Growing media: types and physical/chemical properties. In: REED, D.W. (Ed.) A Growers Guide to Water, Media, and Nutrition for Greenhouse Crops. Batavia: Ball, 1996. p.93-122.

FRIZZONE, J. A.; GONÇALVES, A. C. A.; REZENDE, R. Produtividade do pimentão amarelo, Capsicum annuum L., cultivado em ambiente protegido, em função do potencial mátrico de água no solo. Acta Scientiarum, Maringá-PR, v.23, n.5, p.1111-1116, 2001.

FILGUEIRA, F. A. R. Solanáceas. $1^{\text {a }}$ Ed., Lavras: Editora UFLA, 2003. 333p.

KÄMPF, A. N. Seleção de materiais para uso como substrato. In: KÄMPF, A.N.; FERMINO, M.H. (Eds.). Substratos para plantas: a base da produção vegetal em recipientes. Porto Alegre: Gênesis, 2000. p.139-145.

MUNIZ, J.O.L.; SILVA, L.A.; ALMEIDA, J.J.L. Efeito das adubações orgânica e orgânicaquímica em pepino no litoral do Ceará. Horticultura Brasileira, Brasília, v. 10, n. 1, p. 38-39. 1992.

MIELNICZUK, J. Matéria orgânica e a sustentabilidade de sistemas agrícolas.In: SANTOS, G. A.; CAMARGO, F. A. O. Fundamentos da matéria orgânica do solo: ecossistemas tropicais e subtropicais. Porto Alegre: Gênesis, 1999. p. 1-8.

PEREIRA, A. L. Cultura do Pimentão. Fortaleza: Departamento Nacional de Obras Contra as Secas, 1990. 49p.

SILVA JÚNIOR, A.A. Adubação mineral e orgânica em repolho. Horticultura Brasileira, Brasília, v. 4, n. 2, p.19-21. 1986.

SILVA, M. A. G; BOARETTO, A. E.; MELO, A. M. T.; FERNANDES, H. M G.; SCIVITTARO, W. B. Rendimento e qualidade de frutos de pimentão cultivado em ambiente protegido em função do nitrogênio e potássio aplicados em cobertura. Scientia Agrícola, v. 56, n. 4, p. 1199-1207, 1999.

SANTOS, A. C. V. Biofertilizantes líquidos: o desafio agrícola da natureza. 2 ed. , ver. Niterói: EMATER - Rio, 162p. 1992. (Agropecuária Fluminense, 8).

SANTOS, A. C.; AKIBA, F. Biofertilizantes líquidos: uso correto na agricultura alternativa. Seropédica: Imprensa Universitária/UFRRJ. 1996. 35p.

SOUZA, A. P.; PEREIRA, J. B. A.; SILVA, L. D. B.; GUERRA, J. G. M.; CARVALHO, D. F. Evapotranspiração, coeficientes de cultivo e eficiência do uso da água da cultura do pimentão em diferentes sistemas de cultivo. Acta Scientiarum Agronomy, Maringá, v. 33, n. 1, p. 15-22, 2011.

WENDLING, I.; GATTO, A. Substratos, adubação e irrigação na produção de mudas. Viçosa: Aprenda Fácil Editora. 2002. 166p. 